\title{
POLÍTICAS PÚBLICAS DE FORMAÇÃO PARA O TRABALHO DE PESSOAS COM DEFICIÊNCIA: REVISÃO BIBLIOGRÁFICA
}

\author{
Janete BENJAMIN ${ }^{1}$
}

Universidade do Estado do Pará-UEPA

Gilmar Pereira da SILVA ${ }^{2}$

Universidade Federal do Pará-UFPA

Ivanilde Apoluceno de OLIVEIRA ${ }^{3}$

Universidade do Estado do Pará-UEPA

Resumo: Este artigo trata de uma revisão bibliográfica do tema de pesquisa do doutorado "Políticas Públicas de Formação para o Trabalho de pessoas com deficiência do governo do estado do Pará". O objetivo é analisar resumos das dissertações e teses do banco de dados da CAPES, voltados à profissionalização das $P c D$. A metodologia consiste em pesquisa bibliográfica. $\mathrm{Na}$ busca realizada entre o período de 2013 a 2016, com os descritores Trabalho, Educação, Deficiência e Profissionalização, foram identificadas 9.498 dissertações $e$ 3.932 teses. Entretanto, apenas 8 dissertações e 1 tese estavam diretamente relacionadas ao tema. Resultados: das 9 produções analisadas, 3 buscaram pesquisar programas de formação $e$ profissionalização no SENAI e SENAC, 4 nos Institutos Federais e 2 nas Instituições Filantrópicas. Identificamos que apenas 5 produções apresentam estudos direcionados às políticas públicas dos governos federal e estadual.

Palavras-chave: Trabalho e Educação. Deficiência. Revisão Bibliográfica.

\begin{abstract}
This article deals with a bibliographical review of the research theme of the doctoral dissertation "Public Policies of Training for the Work of Persons with Disabilities of the Government of the State of Pará". The objective is to analyze abstracts of dissertations and theses of the CAPES database, aimed at the professionalization of PcD. The methodology consists of bibliographic research. In the search carried out over the period from 2013 to 2016, with the descriptors: Work; Education; Deficiency and Professionalism were identified 9,498 dissertations and 3,932 theses, however, only 8 dissertations and 1 thesis were directly related to the topic. Results: of the 9 productions analyzed, 3 sought to research training programs and professionalization in SENAI and SENAC, 4 in the Federal Institutes and 2 in the Philanthropic Institutions. We identified that only 5 productions present studies directed to the public policies of the federal and state governments.
\end{abstract}

Keywords: Labor and Education. Deficiency. Literature review.

\footnotetext{
${ }^{1}$ Doutoranda em Educação pela UFPA/PPGED. Mestre em Educação pela UFPA/PPGED. Licenciada em Pedagogia pela UFPA. Professora da UEPA. Técnica em Educação da SEDUC-Pará. Membro do Grupo de Estudos e Pesquisas Trabalho e Educação-GEPTE: janetebenjamim@yahoo.com.br

${ }^{2}$ Doutor em Educação pela UFRN. Vice-reitor da UFPA. Professor do PPGED/UFPA. Coordenador do Grupo de Estudos e Pesquisas Trabalho e Educação-GEPTE: gpsilva@ufpa.br

3 Pós-Doutora em Educação pela PUC-Rio. Doutora em Educação pela PUC-SP/UNAM/UAM-México. Professora do Programa de Pós-Graduação em Educação e Coordenadora do Núcleo de Educação Popular Paulo Freire da Universidade do Estado do Pará. E-mail: nildeapoluceno@hotmail.com
} 


\section{Introdução}

A revisão bibliográfica a respeito do programa de formação para o trabalho destinado a Pessoas com Deficiência (PcD), como processo de inclusão no mercado de trabalho, é um tema relevante para o campo da educação especial. Como estão sendo tratadas, pelos estudantes de mestrado e doutorado em educação, as pesquisas relacionadas e direcionadas ao tema Políticas Públicas de Formação para o Trabalho de pessoas com deficiência? Com este estudo é possível identificar a relevância do tema para a pesquisa na área e, sobretudo, para a educação especial no estado do Pará, lócus de investigação do tema de pesquisa do doutorado.

A revisão bibliográfica apresenta-se como forma de esclarecer as questões teórico-metodológicas pertinentes ao tema, como também faz parte do relatório final da tese em estudo.

O estudo apresenta como objetivo analisar os resumos das dissertações de mestrado e teses de doutorado do banco de dados da Coordenação de Aperfeiçoamento de Pessoal de Nível Superior-CAPES, voltados para a profissionalização das PcD, bem como, contextualizar o problema que nos propomos a investigar, pois, mesmo com as cotas estabelecidas na lei $\mathrm{n}^{\circ} 8213 / 91$, as empresas demitem as PcD alegando falta ou nenhuma formação para o trabalho e baixo nível de escolaridade. As questões norteadoras da tese são: quais são os programas de formação para o trabalho destinado às pessoas com deficiência, ofertados pelo governo do estado do Pará e qual a vinculação com as políticas públicas e educacionais do estado?

Para construção da questão problema, buscou-se, a partir de Gamboa (2012), fazer uma análise das necessidades e, através de indagações, buscar respostas não somente no estado de conhecimento, mas em documentos, leis, decretos, resoluções, entrevistas e em teóricos que discutem as categorias trabalho/educação/deficiência.

No que diz respeito ao problema de pesquisa, Alves-Mazzotti (2012, p. 43) afirma que:

[...] A proposição adequada de um problema de pesquisa exige, portanto, que o pesquisador se situe nesse processo, analisando criticamente o estado atual do conhecimento em sua área de interesse, comparando e contrastando abordagens teórico-metodológicas utilizadas e avaliando o peso e a confiabilidade de resultados de pesquisa, de modo a identificar pontos de consenso, bem como controvérsias, regiões de sombra e lacunas que merecem ser esclarecidas. 
O que precisa ser esclarecido na pesquisa de tese em estudo é o porquê das transferências de responsabilidade dos governos estaduais ao sistema "S" de formação que não aparecem com clareza nos trabalhos analisados. Outra questão relevante e que precisa ser identificada é a metodologia desenvolvida nos programas de formação e qualificação para o trabalho e por qual motivo os programas trazem como conceito a formação para o trabalho, a qualificação profissional, a profissionalização, a qualificação e colocação profissional, assim como outros conceitos que precisam ser esclarecidos por meio de referenciais teóricos e legais.

Trata-se de um estudo realizado no primeiro semestre de 2018, por meio da utilização de técnicas de revisão bibliográfica (ALVES-MAZZOTTI, 2012).

Assim, diante as lacunas encontradas na revisão bibliográfica sobre o tema de interesse, poderemos aprofundar o tema e analisar melhor os resultados da investigação realizada.

\section{Apresentação e os resultados da revisão bibliográfica}

A questão que norteou a revisão bibliográfica foi: quantas dissertações e teses estão tratando das políticas públicas de formação e profissionalização para o trabalho de pessoas com deficiência?

Os descritores utilizados na busca on line das dissertações e teses foram: Trabalho; Educação; Deficiência e Profissionalização.

Neste levantamento, no período de 2013 a 2016, foram encontradas um total de 9.498 dissertações e de 3.932 teses, entretanto, somente foram analisadas 8 dissertações e 1 tese, por estarem vinculadas diretamente com o tema. (Ver quadro 1).

Quadro 1 - Dissertações e Teses levantadas por ano

\begin{tabular}{|l|l|}
\hline BASE DE DADOS & $\begin{array}{l}\text { Catálogo de teses e dissertações/plataforma } \\
\text { Sucupira/CAPES }\end{array}$ \\
\hline ENDEREÇO & $\begin{array}{l}\text { http://catalogodeteses.capes.gov.br/catalogo- } \\
\text { teses }\end{array}$ \\
\hline DESCRITORES & $\begin{array}{l}\text { Trabalho-Educação-Deficiência- } \\
\text { Profissionalização }\end{array}$ \\
\hline $\mathrm{N}^{\circ}$ DE TESES ANALISADAS & 01 \\
\hline $\begin{array}{l}\mathrm{N}^{\circ} \quad \text { DE DISSERTAÇÕES } \\
\text { ANALISADAS }\end{array}$ & 08 \\
\hline ANO 2013 TESES & 837 \\
\hline ANO 2013 DISSERTAÇÕES & 2415 \\
\hline
\end{tabular}




\begin{tabular}{|l|l|}
\hline ANO 2014 DISSERTAÇÕES & 2335 \\
\hline ANO 2014 TESES & 991 \\
\hline ANO 2015 DISSERTAÇÕES & 2395 \\
\hline ANO 2015 TESES & 1014 \\
\hline ANO 2016 DISSERTAÇÕES & 2363 \\
\hline ANO 2016 TESES & 1090 \\
\hline $\begin{array}{l}\text { No DISSERTAÇÕES } \\
\text { ENCONTRADAS }\end{array}$ & 9.498 \\
\hline $\mathrm{N}^{\mathbf{o}}$ TESES ENCONTRADAS & 3.932 \\
\hline
\end{tabular}

Fonte: elaboração com os dados da pesquisa

Os resumos foram analisados na íntegra e, quanto aos que não demonstraram clareza no que se propunham a fazer, tentamos buscar entendimento no trabalho completo, porém, dos nove resumos analisados, conseguimos baixar apenas 3 (três) trabalhos completos. Pressupomos que os 6 (seis), até a data da busca, não se encontravam disponíveis devido a não autorização dos autores aos programas, para publicação na íntegra, o que dificultou maior entendimento acerca do tema das dissertações e teses em estudo.

Nas análises, levou-se em consideração o ano da publicação, o programa de pósgraduação, nível de produção, o tema, os objetivos, os procedimentos metodológicos, sujeitos, deficiência dos sujeitos/alunos, foco, instrumento de coleta, tipo de análise, resultados e considerações finais.

Das produções analisadas duas são de uma mesma instituição e as demais de universidades diferentes, tendo representações nas regiões Norte, Nordeste, Sudeste e Sul, conforme o quadro 2.

Quadro 2 - Produções analisadas no endereço: sucupira.capes.gov.br

\begin{tabular}{|c|c|c|c|c|c|}
\hline DEFESA & DATA & TEMA & AUTOR & PPGED & $\begin{array}{l}\text { PALAVRAS- } \\
\text { CHAVE }\end{array}$ \\
\hline $2016 / 1$ & $13 / 06 / 2016$ & $\begin{array}{l}\text { 1-A Inclusão do estudante } \\
\text { com deficiência } \\
\text { intelectual na educação } \\
\text { superior do IFRN Bento } \\
\text { Gonçalves: um olhar } \\
\text { sobre a mediação docente } \\
\text { (dissertação) }\end{array}$ & $\begin{array}{l}\mathrm{M}^{\mathrm{a}} \text { Isabel } \\
\text { Accorsi }\end{array}$ & $\begin{array}{l}\text { Universidade } \\
\text { de Caxias do } \\
\text { Sul }\end{array}$ & $\begin{array}{l}\text { Mediação } \\
\text { Docente. } \\
\text { Educação } \\
\text { Inclusiva. } \\
\text { Deficiência } \\
\text { Intelectual. } \\
\text { Educação } \\
\text { Superior. } \\
\text { Vygotsky }\end{array}$ \\
\hline $2015 / 1$ & $02 / 02 / 2015$ & $\begin{array}{l}\text { 2-Deficiência intelectual e } \\
\text { trabalho: estudo de caso } \\
\text { dos egressos do programa } \\
\text { Trampolim desenvolvido }\end{array}$ & $\begin{array}{l}\text { Carmelinda } \\
\text { Parizzi }\end{array}$ & $\begin{array}{l}\text { Centro } \\
\text { Universitário } \\
\text { Moura } \\
\text { Lacerda }\end{array}$ & $\begin{array}{l}\text { Trabalho. } \\
\text { Deficiência } \\
\text { Intelectual. } \\
\text { Inclusão. }\end{array}$ \\
\hline
\end{tabular}




\begin{tabular}{|c|c|c|c|c|c|}
\hline & & $\begin{array}{ll}\text { pelo } & \text { SENAC/RP } \\
\text { (dissertação) } & \end{array}$ & & & $\begin{array}{l}\text { Qualificação } \\
\text { Profissional. }\end{array}$ \\
\hline $2013 / 1$ & $07 / 06 / 2013$ & $\begin{array}{l}\text { 3-Inclusão no trabalho de } \\
\text { pessoas com deficiência: } \\
\text { Um estudo da APAE de } \\
\text { Barcarena-PA } \\
\text { (dissertação) }\end{array}$ & $\begin{array}{l}\text { Janete } \\
\text { Benjamin }\end{array}$ & $\begin{array}{l}\text { Universidade } \\
\text { Federal do } \\
\text { Pará }\end{array}$ & $\begin{array}{l}\text { Inclusão. } \\
\text { Deficiência. } \\
\text { Trabalho }\end{array}$ \\
\hline $2015 / 1$ & $30 / 03 / 2015$ & $\begin{array}{l}\text { 4-Educação de pessoas } \\
\text { com deficiência: atuação } \\
\text { dos núcleos de apoio às } \\
\text { pessoas com necessidades } \\
\text { especiais no IFRN } \\
\text { (dissertação) }\end{array}$ & $\begin{array}{l}\text { Gilvana } \\
\text { Galeno } \\
\text { Soares }\end{array}$ & $\begin{array}{l}\text { Universidade } \\
\text { Federal do } \\
\text { Rio Grande } \\
\text { do Norte }\end{array}$ & $\begin{array}{l}\text { Educação } \\
\text { profissional. } \\
\text { Inclusão. Pessoa } \\
\text { com deficiência. }\end{array}$ \\
\hline $2013-1$ & $21 / 02 / 2013$ & $\begin{array}{l}5 \text { A Inclusão de Pessoas } \\
\text { com Deficiência na Rede } \\
\text { Regular de Educação } \\
\text { Profissional } \\
\text { (dissertação) }\end{array}$ & $\begin{array}{l}\text { Diana Rosa } \\
\text { Cavaglieri } \\
\text { Liutheviciene } \\
\text { Cordeiro }\end{array}$ & $\begin{array}{l}\text { Universidade } \\
\text { Estadual } \\
\text { Paulista Júlio } \\
\text { de Mesquita } \\
\text { Filho(Marília) }\end{array}$ & $\begin{array}{l}\text { Inclusão. Pessoas } \\
\text { com deficiência. } \\
\text { Educação } \\
\text { profissional. } \\
\text { Trabalho }\end{array}$ \\
\hline $2016-1$ & $24 / 06 / 2016$ & $\begin{array}{l}6 \text { Inclusão, deficiência e } \\
\text { profissionalização: } \\
\text { experiências } \\
\text { sucedidas } \\
\text { (dissertação) }\end{array}$ & $\begin{array}{l}\text { Humberto } \\
\text { Trigo Milesi }\end{array}$ & $\begin{array}{l}\text { Centro } \\
\text { Universitário } \\
\text { Moura } \\
\text { Lacerda }\end{array}$ & $\begin{array}{l}\text { Inclusão. } \\
\text { Deficiência. } \\
\text { Profissionalização }\end{array}$ \\
\hline $2016-2$ & $15 / 12 / 2016$ & $\begin{array}{l}7 \text { Educação profissional } \\
\text { no Ceará: políticas e } \\
\text { práticas dos centros } \\
\text { técnicos em cenários de } \\
\text { reforma (1990-2010) } \\
\text { (tese) }\end{array}$ & $\begin{array}{l}\text { Antonia } \\
\text { Solange } \\
\text { Pinheiro } \\
\text { Xerez }\end{array}$ & $\begin{array}{l}\text { Universidade } \\
\text { Nove de Júlio }\end{array}$ & $\begin{array}{l}\text { Política. } \\
\text { Reformas. } \\
\text { Educação } \\
\text { Profissional. } \\
\text { Trabalho }\end{array}$ \\
\hline $2016-2$ & $30 / 11 / 2016$ & $\begin{array}{l}8 \text { Inclusão de alunos com } \\
\text { deficiência na educação } \\
\text { profissional e tecnológica } \\
\text { (dissertação) }\end{array}$ & $\begin{array}{lr}\text { M }^{\mathrm{a}} & \text { Heloísa } \\
\text { de } & \text { Melo } \\
\text { Cardoso }\end{array}$ & $\begin{array}{l}\text { Universidade } \\
\text { Federal de } \\
\text { Sergipe }\end{array}$ & $\begin{array}{l}\text { Aluno com } \\
\text { deficiência. } \\
\text { Formação } \\
\text { Profissional. } \\
\text { Inclusão }\end{array}$ \\
\hline $2013-1$ & $30 / 04 / 2013$ & $\begin{array}{l}9 \text { As trilhas possíveis da } \\
\text { inclusão de pessoas com } \\
\text { deficiência na educação } \\
\text { profissional do IFES } \\
\text { Vitória: Narrativas dos } \\
\text { protagonistas } \\
\text { (dissertação) }\end{array}$ & $\begin{array}{l}\text { Joselma de } \\
\text { Vasconcelos } \\
\text { Mendes }\end{array}$ & $\begin{array}{l}\text { Universidade } \\
\text { Federal do } \\
\text { Espírito Santo }\end{array}$ & $\begin{array}{l}\text { Educação } \\
\text { profissional. } \\
\text { Inclusão. Jovens e } \\
\text { adultos }\end{array}$ \\
\hline
\end{tabular}

Fonte: elaboração com os dados da pesquisa

No quadro 3, verificamos que, das produções analisadas, 3 (três) buscaram pesquisar programas de formação e profissionalização no sistema "S" (SENAI e SENAC), 4 (quatro) nos Institutos Federais e 2 (duas) nas Instituições Filantrópicas (APAE e Helena Antipoff).

Identificamos, também, apenas 5 (cinco) produções com estudos direcionados às políticas públicas dos governos federal e estadual. Com isso, acreditamos que o tema da 
pesquisa no doutorado pode ser inédito, devido não identificarmos nenhum estudo de dissertações e teses nos programas de pós-graduação da plataforma Sucupira, voltados para políticas públicas de formação para o trabalho de $\mathrm{PcD}$ do governo de estado.

Quadro 3 - Dissertações e teses sobre políticas públicas de formação para o trabalho de pessoas com deficiência

\begin{tabular}{|c|c|c|c|}
\hline $\begin{array}{l}\text { PRODUÇÃO } \\
\text { ANALISADA }\end{array}$ & $\begin{array}{r}\text { DIMENSÃO } \\
\text { ANALISADA }\end{array}$ & $\begin{array}{c}\text { PROCEDIMENTO DO } \\
\text { MÉTODO }\end{array}$ & $\begin{array}{c}\text { CONSIDERAÇÕES } \\
\text { FINAIS } \\
\text { RESULTADOS }\end{array}$ \\
\hline $\begin{array}{l}\text { 1-A Inclusão do } \\
\text { estudante com } \\
\text { deficiência intelectual na } \\
\text { educação superior do } \\
\text { IFRS Bento Gonçalves: } \\
\text { um olhar sobre a } \\
\text { mediação docente } \\
\text { (dissertação). } \\
\text { OBS: Encontrada na } \\
\text { íntegra. }\end{array}$ & $\begin{array}{c}\text { O processo de } \\
\text { inclusão de um } \\
\text { estudante com } \\
\text { deficiência } \\
\text { intelectual(DI) na } \\
\text { educação superior } \\
\text { tecnológica do } \\
\text { IFRGS, campus de } \\
\text { Bento Gonçalves, } \\
\text { com o foco na } \\
\text { mediação docente. }\end{array}$ & $\begin{array}{c}\text { Pesquisa qualitativa de um } \\
\text { estudo de caso, composto } \\
\text { por entrevistas } \\
\text { semiestruturadas com sete } \\
\text { professores e um aluno com } \\
\text { DI e análise de documentos. } \\
\text { Os dados com os } \\
\text { professores foram } \\
\text { organizados e divididos em } \\
\text { três categorias analíticas: } \\
\text { concepção de } \\
\text { aprendizagem, ação docente } \\
\text { e interação, e os resultados } \\
\text { trabalhados na análise dos } \\
\text { conteúdos em Bardin. }\end{array}$ & 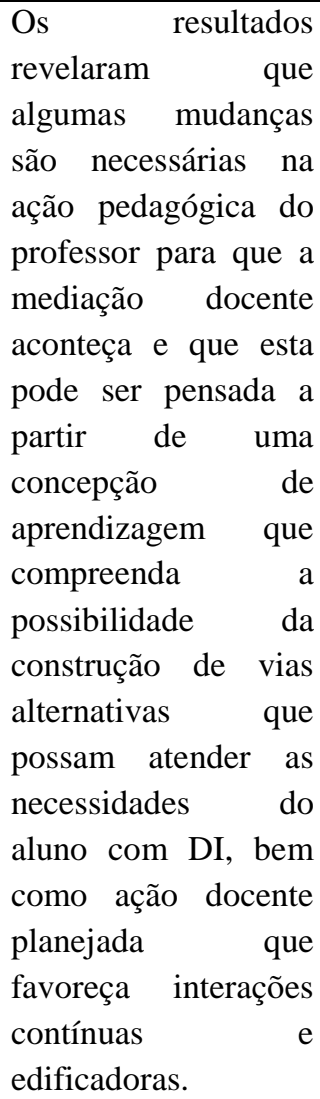 \\
\hline $\begin{array}{l}\text { 2-Deficiência intelectual } \\
\text { e trabalho: estudo de caso } \\
\text { dos egressos do } \\
\text { programa Trampolim, } \\
\text { desenvolvido pelo } \\
\text { SENAC/RP } \\
\text { (dissertação) } \\
\text { OBS: Encontrada na } \\
\text { íntegra. }\end{array}$ & $\begin{array}{lr}\text { As contribuições } \\
\text { do programa } \\
\text { educação para o } \\
\text { trabalho- } \\
\text { Trampolim, } \\
\text { relacionadas ao } \\
\text { processo } \\
\text { inserção de } \\
\text { mercado no } \\
\text { trabalho sob } \\
\text { perspectiva de seus } \\
\text { egressos, } \\
\text { desenvolvido } \\
\text { SENAC/RP. no } \\
\end{array}$ & $\begin{array}{l}\text { Pesquisa de abordagem } \\
\text { qualitativa de um estudo de } \\
\text { caso, realizada com oito } \\
\text { jovens com deficiência } \\
\text { intelectual-DI e deficiência } \\
\text { múltipla-DMU, egressos do } \\
\text { programa Trampolim, nos } \\
\text { anos de } 2011 \text { e 2012, no } \\
\text { município de Ribeirão Preto- } \\
\text { SP. }\end{array}$ & $\begin{array}{l}\text { Os resultados do } \\
\text { estudo mostraram a } \\
\text { influência do } \\
\text { programa Trampolim } \\
\text { na construção da } \\
\text { identidade pessoal, } \\
\text { profissional e social } \\
\text { dos jovens egressos } \\
\text { entrevistados, pois, as } \\
\text { categorias Trabalho, } \\
\text { Emprego, Formação } \\
\text { e Pertencimento aos } \\
\text { grupos sociais, são } \\
\text { universos, } \\
\text { considerados } \\
\text { legítimos }\end{array}$ \\
\hline
\end{tabular}




\begin{tabular}{|c|c|c|c|}
\hline & & & \begin{tabular}{lr} 
formação & de \\
categorias & sociais, \\
\multicolumn{2}{l}{ devido os jovens com } \\
deficiência & se \\
identificar e & serem \\
identificados & pela \\
sociedade. &
\end{tabular} \\
\hline $\begin{array}{l}\text { 3-Inclusão no trabalho de } \\
\text { pessoas com deficiência: } \\
\text { um estudo da APAE de } \\
\text { Barcarena-PA } \\
\text { (dissertação) } \\
\text { OBS: Encontrada na } \\
\text { íntegra. }\end{array}$ & 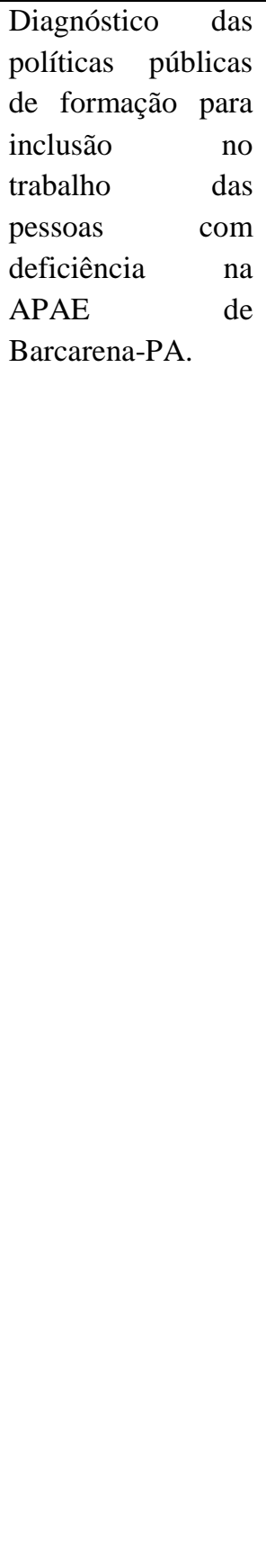 & $\begin{array}{l}\text { Pesquisa qualitativa de um } \\
\text { estudo de caso, numa } \\
\text { abordagem teórica do } \\
\text { materialismo histórico } \\
\text { dialético com oito sujeitos, } \\
\text { dentre eles: } 2 \text { gestores, } 3 \\
\text { professores e } 3 \text { alunos. Na } \\
\text { coleta, foram utilizados } \\
\text { entrevistas, observatório e } \\
\text { registros iconográficos. } \\
\text { Técnica de análise realizada } \\
\text { na análise de conteúdo de } \\
\text { Bardin. }\end{array}$ & 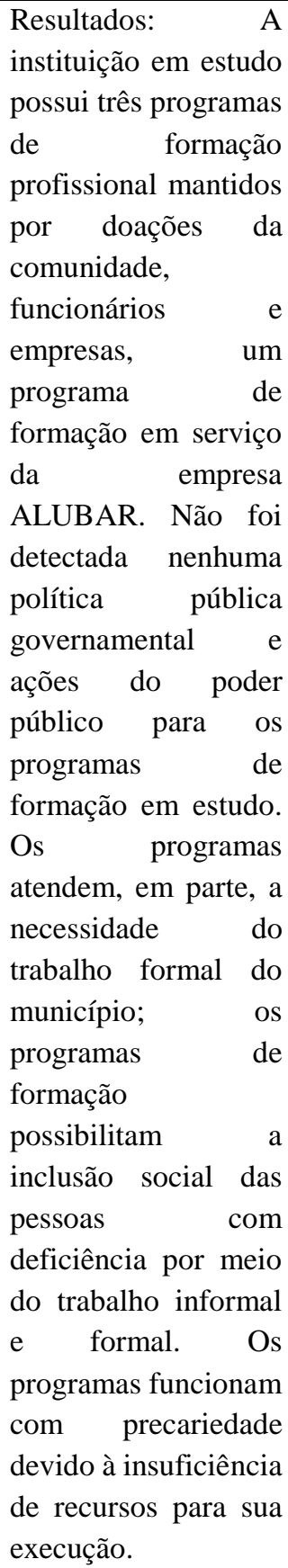 \\
\hline $\begin{array}{lr}\text { 4-Educação de } & \text { pessoas } \\
\text { com deficiência: atuação } \\
\text { dos núcleos de apoio às } \\
\text { pessoas } & \text { com } \\
\text { necessidades } & \text { especiais } \\
\text { no IFRN. } & \\
\text { (dissertação) } & \end{array}$ & $\begin{array}{lr}\text { Avaliação } & \text { da } \\
\text { realidade em que se } \\
\text { encontram } & \text { os } \\
\text { Núcleos } & \text { de } \\
\text { Atendimento } & \text { às } \\
\text { Pessoas } & \text { com } \\
\text { Necessidades } & \end{array}$ & $\begin{array}{l}\text { Pesquisa qualitativa de } \\
\text { caráter } \\
\text { caracterizada pela autora } \\
\text { como estudo de campo, } \\
\text { realizada com treze sujeitos } \\
\text { coordenadores } \\
\text { NAPENEs de diferentes }\end{array}$ & $\begin{array}{l}\text { Os resultados da } \\
\text { pesquisa demonstram } \\
\text { que a criação do } \\
\text { programa TECNEP } \\
\text { significou um grande } \\
\text { avanço para as } \\
\text { políticas de inclusão }\end{array}$ \\
\hline
\end{tabular}




\begin{tabular}{|c|c|c|c|}
\hline & $\begin{array}{l}\text { Educacionais } \\
\text { Especiais-NAPNE, } \\
\text { implantados no } \\
\text { IFRN, por meio do } \\
\text { programa de } \\
\text { educação, } \\
\text { tecnologia } \\
\text { profissionalização } \\
\text { para pessoas com } \\
\text { necessidades } \\
\text { educacionais } \\
\text { especiais } \\
\text { (Programa TEC } \\
\text { NEP). }\end{array}$ & $\begin{array}{l}\text { campis do IFRN, os dados } \\
\text { foram coletados por meio de } \\
\text { questionários, análise } \\
\text { realizada com base na } \\
\text { análise de conteúdo. }\end{array}$ & $\begin{array}{l}\text { no IFRN. } \\
\text { Dificuldades } \\
\text { encontradas pelos } \\
\text { sujeitos da pesquisa } \\
\text { foram: falta de } \\
\text { estrutura física, de } \\
\text { recursos materiais e } \\
\text { humanos e de ordem } \\
\text { financeira, dentre } \\
\text { outros como barreiras } \\
\text { à implementação e } \\
\text { atuação dos } \\
\text { NAPNESs. }\end{array}$ \\
\hline $\begin{array}{l}\text { 5-A Inclusão de Pessoas } \\
\text { com Deficiência na Rede } \\
\text { Regular de Educação } \\
\text { Profissional. } \\
\text { (dissertação) }\end{array}$ & 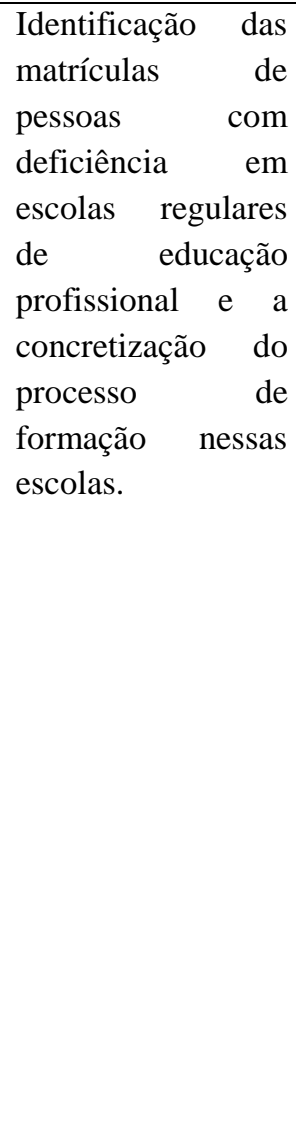 & 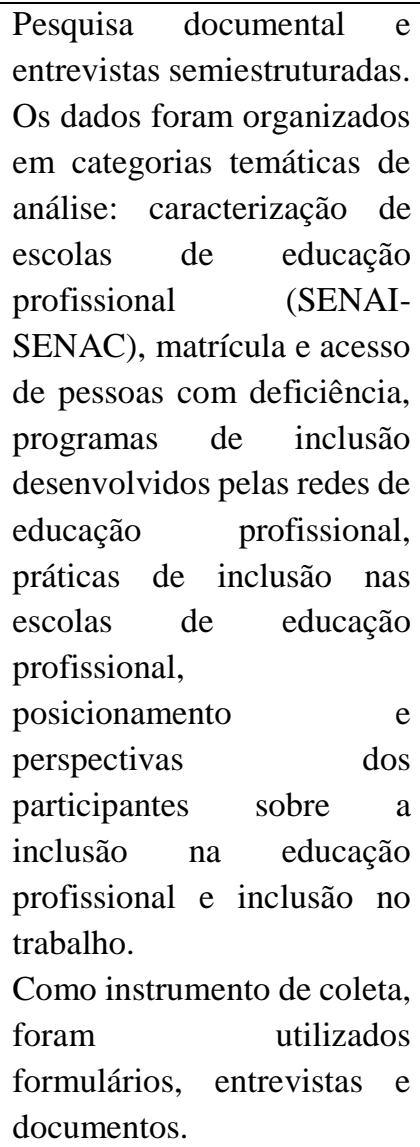 & 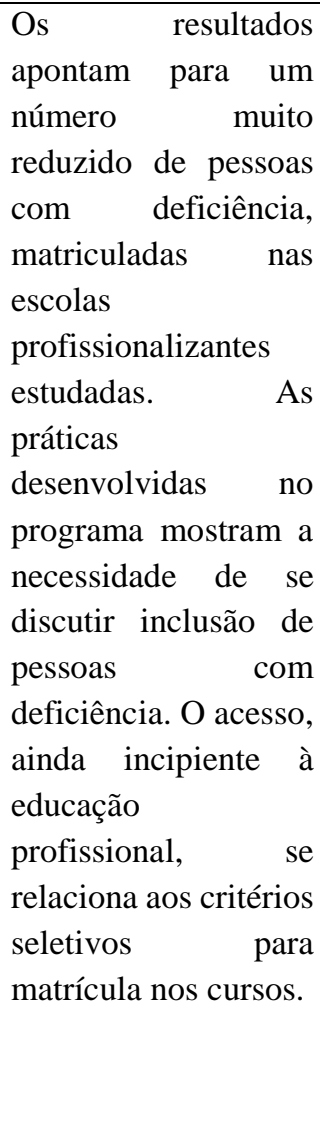 \\
\hline $\begin{array}{l}\text { 6-Inclusão, deficiência e } \\
\text { profissionalização: } \\
\text { experiências bem } \\
\text { sucedidas. } \\
\text { (dissertação) }\end{array}$ & $\begin{array}{lr}\text { Conhecimento } & \text { da } \\
\text { forma como } & \text { os } \\
\text { alunos e egressos } & \text { dosiciencia, } \\
\text { com do } & \text { defici } \\
\text { oriundos } & \text { dos } \\
\text { programas } & \text { doNAC } \\
\text { Ribeirão } & \text { Preto-SP, } \\
\text { percebem } & \text { a } \\
\text { inserção } & \text { das } \\
\text { pessoas } & \text { com } \\
\text { deficiência } & \text { no }\end{array}$ & $\begin{array}{l}\text { Pesquisa qualitativa, } \\
\text { realizada por meio de } \\
\text { entrevistas com cinco } \\
\text { alunos/sujeitos, dentre eles, } \\
4 \text { com deficiência intelectual } \\
\text { e } 1 \text { com deficiência física, e } \\
5 \text { representantes de empresas } \\
\text { de Ribeirão Preto-SP que } \\
\text { participam dos programas de } \\
\text { inclusão do SENAC. }\end{array}$ & $\begin{array}{l}\text { Os resultados } \\
\text { apontaram que há } \\
\text { preocupação, por } \\
\text { parte da empresa, em } \\
\text { ajustar suas } \\
\text { atividades laborais ao } \\
\text { ambiente de trabalho } \\
\text { e que a qualificação } \\
\text { dos participantes foi } \\
\text { favorável a sua } \\
\text { ambientação, o que } \\
\text { indica reais } \\
\text { possibilidades de }\end{array}$ \\
\hline
\end{tabular}




\begin{tabular}{|c|c|c|c|}
\hline & $\begin{array}{l}\text { ambiente do } \\
\text { trabalho. }\end{array}$ & & $\begin{array}{l}\text { oportunidades de } \\
\text { trabalho. O resultado } \\
\text { com os representantes } \\
\text { das empresas aponta } \\
\text { que o processo de } \\
\text { contratação se depara } \\
\text { com pouca oferta de } \\
\text { pessoas qualificadas. } \\
\text { A autora concluiu que } \\
\text { os programas de } \\
\text { qualificação } \\
\text { profissional } \\
\text { contribuem } \\
\text { maneira significativa } \\
\text { com a inclusão de } \\
\text { pessoas } \\
\text { deficiências, quando } \\
\text { há parcerias entre } \\
\text { empregadores } \\
\text { instituições de ensino } \\
\text { e quando há } \\
\text { acompanhamento das } \\
\text { atividades e análise } \\
\text { do desempenho do } \\
\text { profissional com } \\
\text { deficiência. }\end{array}$ \\
\hline $\begin{array}{l}\text { 7-Educação profissional } \\
\text { no Ceará: políticas e } \\
\text { práticas dos centros } \\
\text { técnicos em cenários de } \\
\text { reforma (1990-2010). } \\
\text { (tese) }\end{array}$ & 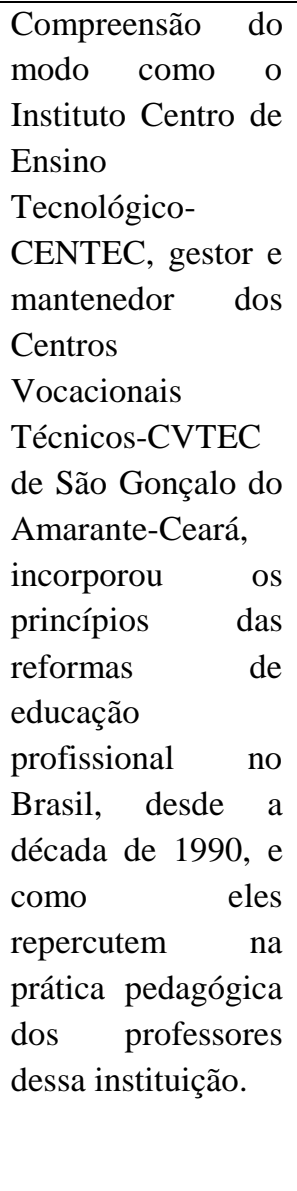 & $\begin{array}{l}\text { Pesquisa documental, em } \\
\text { que foi utilizada a legislação } \\
\text { em vigor, os planos dos } \\
\text { governos das últimas } \\
\text { décadas, as mensagens } \\
\text { destes governos à } \\
\text { Assembleia Legislativa, } \\
\text { documentos sobre o projeto } \\
\text { PROCEM, plano integrado } \\
\text { de educação profissional e } \\
\text { tecnológica do estado do } \\
\text { Ceará, estatuto, regimento e } \\
\text { proposta pedagógica do } \\
\text { Instituto CENTEC. }\end{array}$ & $\begin{array}{l}\text { O estudo aponta uma } \\
\text { ausência do estado do } \\
\text { Ceará na oferta da } \\
\text { educação profissional } \\
\text { até 1995, quando foi } \\
\text { implementada a } \\
\text { secretaria de ciência e } \\
\text { tecnologia e educação } \\
\text { superior-SECITECE. } \\
\text { Com a lei federal } \\
\text { no5154/2004, } \\
\text { surgiram as unidades } \\
\text { dos CVTECs. Em } \\
\text { 2008, o governo } \\
\text { inaugurou uma rede } \\
\text { de expansão dos } \\
\text { cursos técnicos de } \\
\text { nível médio, na } \\
\text { modalidade } \\
\text { integrada, vinculada à } \\
\text { Secretaria } \\
\text { Educação Básica- } \\
\text { SEDUC e começou a } \\
\text { reduzir o atendimento } \\
\text { pela Secretaria da } \\
\text { Ciência, Tecnologia e }\end{array}$ \\
\hline
\end{tabular}




\begin{tabular}{|c|c|c|c|}
\hline & & & $\begin{array}{l}\text { Educação Superior- } \\
\text { SECITECE, } \\
\text { transferindo algumas } \\
\text { unidades para o } \\
\text { Instituto Federal de } \\
\text { Educação, Ciência e } \\
\text { Tecnologia do Ceará- } \\
\text { IFCE. }\end{array}$ \\
\hline $\begin{array}{l}8 \text { Inclusão de alunos com } \\
\text { deficiência na educação } \\
\text { profissional } \\
\text { tecnológica. }\end{array}$ & $\begin{array}{l}\text { Analisa os } \\
\text { dispositivos para a } \\
\text { inclusão do aluno } \\
\text { com deficiência } \\
\text { nos cursos de } \\
\text { formação } \\
\text { profissional do } \\
\text { Instituto Federal de } \\
\text { Educação, Ciência } \\
\text { e Tecnologia de } \\
\text { Sergipe - Campus } \\
\text { Aracajú, no } \\
\text { período de } 2007 \text { a } \\
\text { 2016. }\end{array}$ & $\begin{array}{l}\text { Pesquisa qualitativa com } \\
\text { uma estratégia metodológica } \\
\text { de um estudo de caso, por } \\
\text { meio de observação e da } \\
\text { investigação de pessoas. } \\
\text { Utilizou-se como } \\
\text { instrumento para coleta de } \\
\text { dados, entrevistas } \\
\text { semiestruturadas com } \\
\text { diretor, com coordenadores e } \\
\text { pedagogos. A coleta dos } \\
\text { alunos com deficiência } \\
\text { matriculados e egressos, } \\
\text { assim como com os } \\
\text { professores, foi feita por } \\
\text { meio de um questionário } \\
\text { composto por perguntas } \\
\text { abertas e fechadas, } \\
\text { totalizando } 36 \text { sujeitos. }\end{array}$ & $\begin{array}{l}\text { O estudo revelou que } \\
\text { a inclusão não se } \\
\text { concretiza pelo } \\
\text { simples fato de ser } \\
\text { assegurado o ingresso } \\
\text { desse aluno no } \\
\text { sistema educacional, } \\
\text { mesmo com as } \\
\text { conquistas e o } \\
\text { amparo legal, a } \\
\text { transformação da } \\
\text { escola em um espaço } \\
\text { para todos, ainda se } \\
\text { constitui um desafio. } \\
\text { Bem como o estudo } \\
\text { revelou ainda que a } \\
\text { garantia da oferta de } \\
\text { formação profissional } \\
\text { para alunos com } \\
\text { deficiência, apesar de } \\
\text { se constituir como } \\
\text { avanço, não garante } \\
\text { condições suficientes } \\
\text { para que essas } \\
\text { pessoas tenham } \\
\text { acesso no mundo do } \\
\text { trabalho. }\end{array}$ \\
\hline $\begin{array}{l}9 \text { As trilhas possíveis da } \\
\text { inclusão de pessoas com } \\
\text { deficiência na educação } \\
\text { profissional do IFES- } \\
\text { Vitória: Narrativas dos } \\
\text { protagonistas } \\
\text { (dissertação na íntegra) }\end{array}$ & \begin{tabular}{lr} 
Análise & do \\
\multicolumn{2}{l}{ desenvolvimento } \\
da inclusão & de \\
pessoas & com \\
deficiência & no \\
curso técnico & em \\
segurança & do \\
trabalho do & IFES- \\
Vitória, r na \\
perspectiva r dos \\
sujeitos envolvidos \\
\multicolumn{2}{l}{ no processo. }
\end{tabular} & $\begin{array}{l}\text { Dissertação, pesquisa } \\
\text { qualitativa, interpretativa de } \\
\text { um estudo de caso com dez } \\
\text { sujeitos, dentre eles, } \\
\text { deficiente físico, professores } \\
\text { do curso, gestores, pedagogo } \\
\text { e diretor de ensino. Além da } \\
\text { entrevista, foi realizada } \\
\text { análise legal e documental. } \\
\text { O estudo foi realizado no } \\
\text { ano de } 2012 \text {. }\end{array}$ & $\begin{array}{l}\text { Os resultados do } \\
\text { estudo revelaram que } \\
\text { os sujeitos se narram } \\
\text { ao processo da } \\
\text { inclusão vivido na } \\
\text { instituição desde o } \\
\text { início como processo } \\
\text { de conquista e a } \\
\text { valorização da } \\
\text { experiência vivida. }\end{array}$ \\
\hline
\end{tabular}

Fonte: elaboração com os dados da pesquisa

Quanto ao foco do estudo identificado nas produções, está voltado para inclusão de PcD em programas de formação para o trabalho, sendo que sete expõem claramente 
os programas, um deles explicita a mediação docente, mas com ênfase no programa de formação, e um expõe o núcleo de apoio às $\mathrm{PcD}$, direcionado aos programas de formação.

Quadro 4 - Foco de estudo

\begin{tabular}{|c|c|}
\hline FOCO DE ESTUDO & $\mathrm{N}^{\mathrm{o}}$ \\
\hline $\begin{array}{c}\text { Inclusão de alunos com deficiência nos Institutos Federais } \\
\text { Tecnológicos }\end{array}$ & 1 \\
\hline Centro de Ensino Tecnológico & 1 \\
\hline Inclusão em escolas de educação profissional & 1 \\
\hline Mediação docente & 1 \\
\hline Alunos deficientes & 2 \\
\hline Programa de formação para deficientes & 2 \\
\hline Núcleo de apoio às PcD & 1 \\
\hline
\end{tabular}

Fonte: elaboração com os dados da pesquisa

Em termos metodológicos, sobre os tipos de pesquisa descritos no quadro 3, observamos que cinco se apresentam como pesquisa qualitativa do tipo estudo de caso, uma pesquisa qualitativa de pesquisa de campo, uma pesquisa qualitativa e duas pesquisas documentais (Ver quadro 5). Quatro identificaram o tipo de análise como Análise do Conteúdo e cinco não apresentaram em seus resumos essa característica.

Quadro 5 - Tipos de Pesquisa

\begin{tabular}{|c|c|}
\hline TIPO DE PESQUISA & $\mathrm{N}^{\mathbf{0}}$ \\
\hline Pesquisa qualitativa & 1 \\
\hline $\begin{array}{c}\text { Pesquisa qualitativa do tipo estudo de } \\
\text { caso }\end{array}$ & 5 \\
\hline $\begin{array}{c}\text { Pesquisa qualitativa de um estudo de } \\
\text { campo }\end{array}$ & 1 \\
\hline Pesquisa documental & 2 \\
\hline
\end{tabular}

Fonte: elaboração com os dados da pesquisa

Dentre os instrumentos de coleta utilizados nas produções analisadas, destaca-se a entrevista acrescida da análise documental. Mas foram também utilizados a entrevista, aplicação de questionário, levantamento documental e a observação (Quadro 6).

Quadro 6 - Instrumentos metodológicos

\begin{tabular}{|c|c|}
\hline INSTRUMENTO & $\mathrm{N}^{\circ}$ \\
\hline Entrevistas & 2 \\
\hline Entrevistas + documentos & 3 \\
\hline Questionários & 1 \\
\hline $\begin{array}{c}\text { Documentos, entrevistas, observação } \\
\text { registros iconográficos }\end{array}$ & 1 \\
\hline Documentos & 1 \\
\hline
\end{tabular}




\section{Questionários, observação e entrevistas \\ Fonte: elaboração com os dados da pesquisa}

Entre os sujeitos, a maioria das pesquisas não informou o tipo de deficiência. Entretanto, foram encontrados sujeitos com Deficiência Intelectual e Deficiências Múltiplas, Deficiência Intelectual, Deficiência Física e Deficiência Intelectual, bem como Deficiência Física (Quadro 7).

Quadro 7 - Sujeitos mencionados nas produções: tipos de deficiência

\begin{tabular}{|c|c|}
\hline $\begin{array}{c}\text { TIPO DE DEFICIÊNCIA } \\
\text { DOS SUJEITOS }\end{array}$ & $\mathrm{N}^{\circ}$ \\
\hline DI & 1 \\
\hline DI +DMU & 1 \\
\hline DF+DI & 1 \\
\hline DF & 1 \\
\hline Não informada & 5 \\
\hline
\end{tabular}

Fonte: elaboração com os dados da pesquisa

Dentre as categorias de análise presentes na produção, destaca-se que a categoria deficiência apresenta-se de forma explícita em quatro produções, estando presentes três pessoas com deficiência intelectual, duas com deficiência física e uma com deficiências múltiplas, porém, as nove produções analisadas apresentam em seus objetos de estudo apenas a categoria deficiência.

$\mathrm{Na}$ análise das 9 produções, constatou-se que há consenso nas seguintes situações:

1- Os programas de formação para o trabalho destinado à $\mathrm{PcD}$ trazem um grande avanço para as políticas de inclusão social por meio do trabalho formal e informal;

2- A falta de estrutura física, de recursos materiais, humanos e financeiro dificulta o melhor andamento do trabalho com os PcD nos programas de formação que dependem dos governos estaduais e federal;

3- Algumas mudanças na ação do professor são necessárias para que aconteça o aprendizado significativo dos alunos com deficiência, dentre elas, adequações curriculares nos planejamentos docentes;

4- Os programas e as práticas demonstram a importância da discussão sobre inclusão para as PcD em escolas de educação profissional;

5- Influência dos programas de formação e qualificação profissional na formação da identidade pessoal, profissional e social das pessoas com deficiência;

6- Nos programas com exigência de escolaridade (Ensino Fundamental II e Ensino Médio), ainda apresentam números reduzidos de PcD em suas matrículas; 
7- Empresas contratam pessoas com deficiência intelectual pela obrigatoriedade da lei e fiscalização do Ministério do Trabalho e Emprego-MTE, não pela formação;

8- Empresas demitem Pessoas com Deficiência Intelectual-DI, alegando falta de escolaridade, qualificação profissional e inadequações arquitetônicas.

Diante a todos os fatos apresentados, os de número 6,7 e 8 , se confirmaram em pesquisa exploratória e de campo, realizada para construção da tese, atribui-se o fato de número 6 ao nível de escolaridade, principalmente do aluno com DI, e a exigência de escolaridade dos programas de qualificação em seus editais. Quanto aos fatos de número 7 e 8, a lei $N^{o} 8213 / 91$, que estabelecem as cotas de inclusão no trabalho, e a Lei $n^{\circ}$ 10.098/2000, que estabelecem normas gerais e critérios básicos para a promoção da acessibilidade das $\mathrm{PcD}$ ou com mobilidade reduzida, não apresentam exigências de escolaridade para ocupação das cotas nas empresas e dizem que a formação deve se dar em serviço e formação oferecidos pelas mesmas. No que diz respeito às adequações arquitetônicas, a lei 10.098/2000 se estende a órgãos públicos e privados, portanto, as empresas também se enquadram nas normas legais, o que falta é mais fiscalização dos órgãos competentes e exigências para que as empresas cumpram as leis.

\section{Considerações finais}

Os resultados mostraram que nos programas de pós-graduação em educação, a temática voltada para profissionalização de PcD ainda é pouca explorada. Contudo, os estudos analisados deixaram claro que o êxito das pessoas com deficiência nos programas de formação para o trabalho e no mercado de trabalho só é possível pela combinação de fatores como professores comprometidos com a causa das $\mathrm{PcD}$, adaptações curriculares coerentes com os conteúdos trabalhados, adaptações do espaço físico da escola e no ambiente de trabalho, utilização de tecnologias adequadas, sensibilização e a conscientização de todos os colegas de classe e, acima de tudo, com políticas públicas coerentes por parte do poder público.

O levantamento bibliográfico realizado nas dissertações e nas teses ligadas diretamente ao tema, nos fez perceber que alguns pontos que podiam ser abordados já estão publicados nas produções analisadas, fazendo com que modificássemos a interpretação dos fatos constatados em lócus.

Outro fator relevante foi a confirmação de pontos levantados na pesquisa exploratória e na pesquisa de campo realizada por meio de entrevistas com sujeitos ligados diretamente ao objeto da tese em construção que, em suas falas, confirmam o que 
as produções realizadas em outros estados apresentam como problemáticas para a inclusão no trabalho de pessoas com deficiência, tais como, demissão de PcD intelectual com a justificativa de que estes não têm escolaridade e nem qualificação profissional, assim como admissão de deficientes intelectuais por determinação do Ministério Público do Trabalho, por exigência da lei e não por escolaridade.

Essas confirmações nos trouxeram uma forte curiosidade em acrescentar na pesquisa como está sendo concebida a terminalidade específica para deficientes no estado do Pará, pois compreendemos que a categoria de deficiência mais prejudicada com a inclusão tanto escolar quanto no trabalho é a dos deficientes intelectuais.

\section{Referências}

ACCORSI, Maria Isabel. A inclusão do estudante com deficiência intelectual na educação superior do IFRS Bento Gonçalves: Um olhar sobre a mediação docente. Caxias do Sul, Dissertação de mestrado-PPGED Caxias do Sul, 2016.

ALVES-MAZZOTTI, Alda Judith. A "revisão da bibliografia" em teses e dissertações: meus tipos inesquecíveis - o retorno In: BIANCHETTI, Lucídio; MACHADO, Ana Maria Netto (org.). A bússola do escrever: desafios e estratégias na orientação e escrita de teses e dissertações. São Paulo: Cortez, 2012.

BENJAMIN, Janete. Inclusão no trabalho de pessoas com deficiência: Um estudo da APAE de Barcarena-PA. Belém-PA, Dissertação de mestrado- PPGED-UFPA, 2013.

BRASIL, Lei na 10.098/2000. In: http://www2.camara.leg.br/legin/fed/lei/2000/lei10098-19-dezembro-2000 Acesso em 05 de agosto de 2018.

CARDOSO, Maria Heloísa de Melo. Inclusão de alunos com deficiência na educação profissional e tecnológica. São Cristovão-SE, Dissertação de mestrado-NPGED-UFS, 2016.

CORDEIRO, Diana Rosa Cavagliere Liutheviciene. A inclusão de pessoas com deficiência na rede regular de educação profissional. Marília-SP, Dissertação de mestrado-PPGED-UNESP/Marília, 2013.

GAMBOA, Silvio Sánchez. Pesquisa em educação: métodos e epistemologias-Chapecó: Argos, 2012.

MENDES, Josselma de Vasconcelos. As trilhas possíveis da inclusão de pessoas com deficiência na educação profissional do IFES Vitória: narrativas dos protagonistas. Espírito Santo, Dissertação de mestrado-PPGED-UFES, 2013.

MILESI, Humberto Trigo. Inclusão, deficiência e profissionalização: experiências bem sucedidas. Ribeirão Preto-SP, Dissertação de mestrado-PPGE-Centro Universitário Moura Lacerda, 2016.

PARIZZI, Carmelinda. Deficiência intelectual e trabalho: um estudo de caso dos egressos do programa Trampolim desenvolvido pelo SENAC/RP. Ribeirão Preto Dissertação de mestrado - PPGED - Centro Universitário Moura Lacerda, 2015. 
SILVA, Gisene Daura Pereira da. As meninas de Helena: deficiência intelectual, inclusão e mercado de trabalho em São Luis. São Luis-MA, Dissertação de mestradoPPGED-UFMA, 2013.

SOARES, Gilvana Galeno. Educação profissional de pessoas com deficiência: atuação dos núcleos de apoio às pessoas com necessidades educacionais especiais no IFRN. NatalRN, Dissertação de mestrado-PPGED-UFRN, 2015.

XEREZ, Antonia Solange Pinheiro. Educação profissional no Ceará: políticas e práticas dos centros técnicos em cenários de reforma (1990-2010). Barra Funda- SP, Tese de doutorado- PPGED-UNINOVE, 2013. 